\title{
Factors associated with good self-rated health and quality of life in subjects with self-reported COPD
}

This article was published in the following Dove Press journal:

International Journal of COPD

6 October 2011

Number of times this article has been viewed

\author{
Mats Arne ${ }^{1,2}$ \\ Fredrik Lundin' \\ Gunnar Boman² \\ Christer Janson ${ }^{2}$ \\ Staffan Janson ${ }^{1,3}$ \\ Margareta Emtner 2,4 \\ 'Primary Care Research Unit, \\ County Council of Värmland, \\ Universitetsgatan 3, Karlstad, Sweden; \\ ${ }^{2}$ Department of Medical Sciences, \\ Respiratory Medicine and Allergology, \\ Uppsala University, Uppsala, Sweden; \\ ${ }^{3}$ Department of Social Sciences, \\ Division of Public Health, Karlstad \\ University, Karlstad, Sweden; \\ ${ }^{4}$ Department of Neuroscience, \\ Physiotherapy, Uppsala University, \\ Uppsala, Sweden
}

Background: Recent guidelines for chronic obstructive pulmonary disease (COPD) state that COPD is both preventable and treatable. To gain a more positive outlook on the disease it is interesting to investigate factors associated with good, self-rated health and quality of life in subjects with self-reported COPD in the population.

Methods: In a cross-sectional study design, postal survey questionnaires were sent to a stratified, random population in Sweden in 2004 and 2008. The prevalence of subjects (40-84 years) who reported having COPD was $2.1 \%$ in 2004 and $2.7 \%$ in 2008. Data were analyzed for 1475 subjects. Regression models were used to analyze the associations between health measures (general health status, the General Health Questionnaire, the EuroQol five-dimension questionnaire) and influencing factors.

Results: The most important factor associated with good, self-rated health and quality of life was level of physical activity. Odds ratios for general health varied from 2.4 to 7.7 depending on degree of physical activity, where subjects with the highest physical activity level reported the best health and also highest quality of life. Social support and absence of economic problems almost doubled the odds ratios for better health and quality of life.

Conclusions: In this population-based public health survey, better self-rated health status and quality of life in subjects with self-reported COPD was associated with higher levels of physical activity, social support, and absence of economic problems. The findings indicated that of possible factors that could be influenced, promoting physical activity and strengthening social support are important in maintaining or improving the health and quality of life in subjects with COPD. Severity of the disease as a possible confounding effect should be investigated in future population studies.

Keywords: chronic obstructive pulmonary disease, health status, physical activity, quality of life, social support

\section{Introduction}

Chronic obstructive pulmonary disease (COPD) is a major public health problem in persons over $40 .{ }^{1}$ Further increases in the prevalence and mortality of COPD can be expected over the coming decades. ${ }^{2}$ People in general had little knowledge about the disease, ${ }^{3}$ but during the last decade COPD has become a widely recognized disease entity. Those with self-reported COPD in the adult population can now be identified and questioned about their health status and quality of life.

The World Health Organization (WHO) (1948) defines health as "a state of complete physical, mental and social well-being and not merely the absence of disease or infirmity". In later years, a salutogenic approach focusing on factors supporting health and well-being has successively been introduced ${ }^{4}$ and was supported by the WHO
Correspondence: Mats Arne Primary Care Research Unit, Universitetsgatan 3, SE-656 37 Karlstad, Sweden

Tel +46706533259

Fax +46 546I6954

Email mats.arne@medsci.uu.se 
Ottawa Charter of $1986,{ }^{5}$ which advocated a reorientation of health services towards the promotion of health. Knowledge about predictors of good health can support health-promoting activities among individuals with chronic disorders. ${ }^{6}$ Thus, a health-promoting society for healthy people as well as for those with chronic diseases could be created, both at societal and individual levels. ${ }^{7}$

We have previously shown that subjects with chronic disease have a low general health status and a low level of physical activity compared with healthy subjects. ${ }^{8}$ Subjects with COPD are particularly restricted in their activities. Patients with COPD can be impaired in all domains of healthrelated quality of life $^{9}$ and depression in patients with COPD seems associated with poor exercise performance and lower health status. ${ }^{10}$ Studies often focus on risk factors and negative aspects, with a focus on ill-health, ${ }^{11}$ while determinants of good health have been studied less extensively. ${ }^{12}$

Recent guidelines for COPD state that COPD is both preventable and treatable. ${ }^{2}$ In addition, the importance of increasing awareness of COPD, to promote a healthy lifestyle and encourage physical activity in all patients with COPD has been emphasized. ${ }^{13}$ Therefore, investigating factors associated with good health in subjects with COPD is of great interest.

The aim of this study was to investigate factors associated with good, self-rated health and quality of life in subjects with self-reported COPD.

\section{Study population and methods Study population}

Two population surveys including men and women were performed in 2004 and 2008. Data were obtained in AugustNovember 2004 and March-April 2008 using a postal survey questionnaire in Swedish. The area investigated covered 55 municipalities in five counties in central Sweden with approximately one million inhabitants. The sampling was random after stratification for gender, age group, county, and municipality. Data collection was completed after two postal reminders.

In the studied subsample of the present study (age group 40-84 years) the questionnaire was sent to 45,657 persons (2004) and 45,959 persons (2008) (Figure 1). A total of 31,606 (2004) and 30,582 (2008) persons answered the questionnaire with a response rate of $69.2 \%$ (2004) and

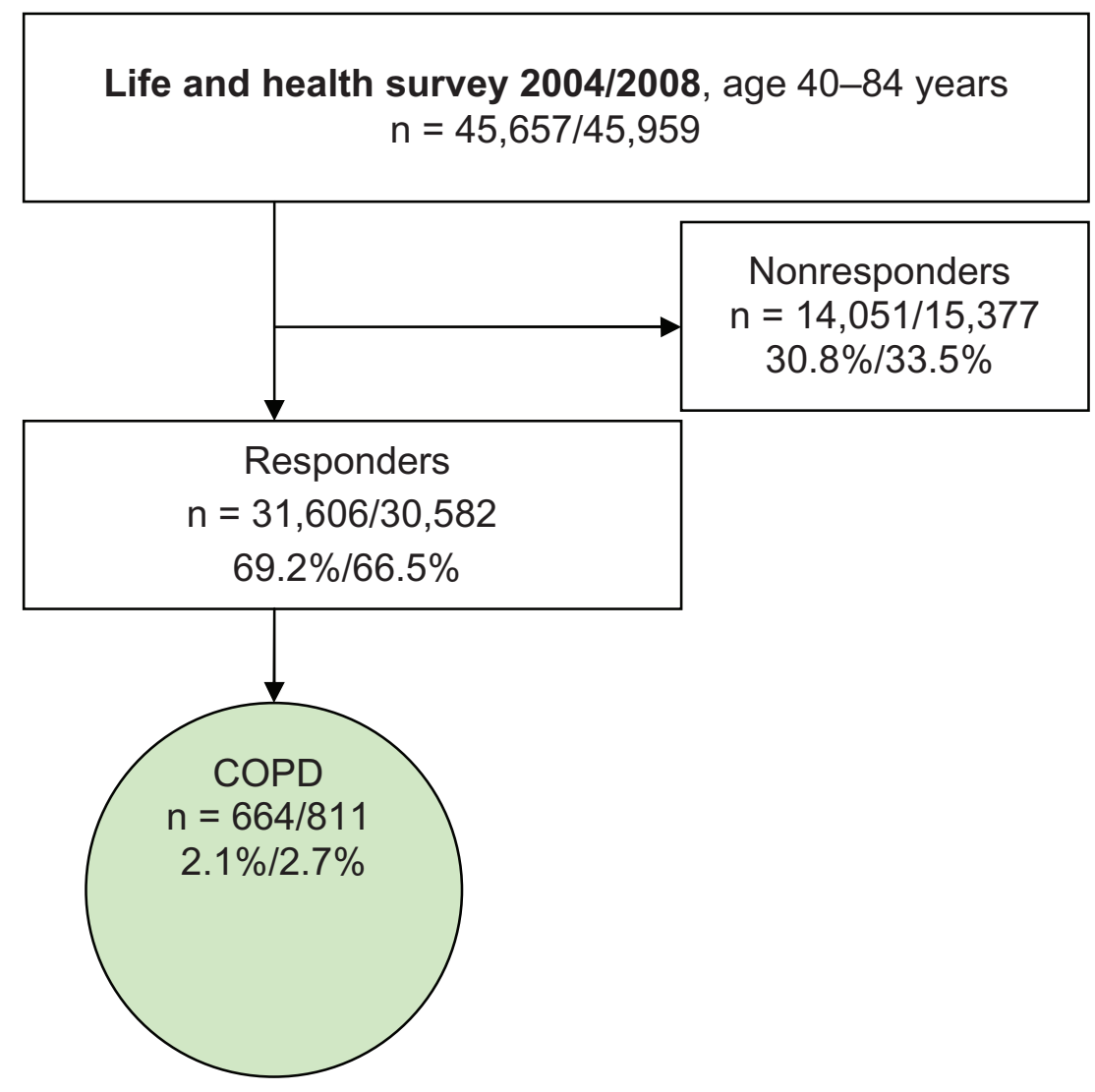

Figure I Selection of the population surveyed.

Abbreviation: COPD, chronic obstructive pulmonary disease. 
66.5\% (2008). All subjects who answered "Yes, COPD" to the question "Have you or have you had any of the following longstanding diseases or problems during the past 12 months", were included (Table 1). The prevalence of subjects who stated having COPD in the sample was $2.1 \%$ in 2004 and $2.7 \%$ in 2008. Due to the low reported prevalence of COPD, the results from the two surveys were combined to obtain a larger population for analysis. The probability of the same person answering both surveys was $2.4 \%$ and this possible overlap was assessed as not influencing results.

\section{Methods}

The factors associated with health status and quality of life in those with self-reported COPD were analyzed.
Outcome variables - health status and quality of life

General health status was assessed by the answer to the question "How do you rate your general health status?" with the alternatives; "Very good/Good/Neither good nor poor/ Poor/Very poor". ${ }^{14}$

The General Health Questionnaire (GHQ) is a self-reported questionnaire designed to identify psychological disorders, mainly within the anxiety/depression spectrum. In the present study the 12-item version (GHQ12) was used. ${ }^{15}$ Scores were calculated from dichotomizing the 12 items $(0=$ equal or better than usual, 1 = worse than usual), and psychological distress was defined as present when the total score was 3 or higher.

The EuroQol five-dimension questionnaire (EQ-5D), consists of the five dimensions: mobility, self-care, usual

Table I Characteristics of the subjects $(n=1475)$

\begin{tabular}{|c|c|c|c|c|}
\hline & $\begin{array}{l}\text { Combined } \\
2004+2008 \\
n=\text { I } 475\end{array}$ & $\begin{array}{l}2004 \\
n=664\end{array}$ & $\begin{array}{l}2008 \\
n=8 I I\end{array}$ & $P$ value \\
\hline Age (years) & $69.1(9.7)$ & $68.9(9.8)$ & $69.3(9.6)$ & 0.25 \\
\hline Female sex (\%) & 46.0 & 43.8 & 47.8 & 0.06 \\
\hline $\mathrm{BMI}\left(\mathrm{kg} / \mathrm{m}^{2}\right)$ & $26.1(5.0)$ & $25.9(4.7)$ & $26.3(5.3)$ & 0.10 \\
\hline Economic problems (\%) & 15.0 & 16.1 & $14 . \mid$ & 0.296 \\
\hline Alcohol use the past 12 months (\%) & & & & 0.678 \\
\hline $2-4$ times a month or more & 48.7 & 48.1 & 49.2 & \\
\hline Once a month or less/never & 51.3 & 51.9 & 50.8 & \\
\hline Educational level (\%) & & & & 0.001 \\
\hline Compulsory school & 57.3 & 67.8 & 54.7 & \\
\hline Grammar school & 16.1 & 13.2 & 18.5 & \\
\hline University & 12.3 & II.I & 13.3 & \\
\hline Other & 10.9 & 7.8 & 13.4 & \\
\hline Social support (\%) & & & & 0.422 \\
\hline No & 9.1 & 9.1 & 9.1 & \\
\hline Yes, probably & 26.3 & 27.9 & 24.9 & \\
\hline Yes, certainly & 64.6 & 63.0 & 66.0 & \\
\hline Smoking status (\%) & & & & 0.179 \\
\hline Never smokers & 12.3 & 13.6 & 11.2 & \\
\hline Ex-smokers & 54.6 & 52.2 & 56.6 & \\
\hline Current smokers & 33.1 & 34.2 & 32.2 & \\
\hline Physical activity (\%) & & & & 0.828 \\
\hline Sedentary & 39.3 & 40.5 & 38.3 & \\
\hline Moderate exercise (low activity) & 43.7 & 43.4 & 44.0 & \\
\hline Moderate regular exercise & 11.4 & 10.8 & 11.9 & \\
\hline Regular exercise and training & 5.6 & 5.3 & 5.8 & \\
\hline Employment status (\%) & & & & 0.423 \\
\hline Employed or studying & 17.1 & 15.6 & 18.3 & \\
\hline Sick leave or sickness pension & 13.6 & 13.7 & 13.6 & \\
\hline Retired & 69.3 & 70.7 & 68.1 & \\
\hline \multicolumn{5}{|l|}{ Comorbidity factors (\%) } \\
\hline Cardiovascular disease & 33.8 & 35.5 & 32.5 & 0.11 \\
\hline Hypertension & 45.3 & 44.9 & 45.5 & 0.41 \\
\hline Asthma & 42.8 & 45.9 & 40.3 & 0.02 \\
\hline Depression & 26.2 & 27.3 & 25.3 & 0.19 \\
\hline Chronic fatigue syndrome & 21.8 & 23.3 & 20.6 & 0.11 \\
\hline
\end{tabular}

Notes: Economic problems, difficulty in managing current expenditure during the past 12 months. Data are presented as mean (standard deviation) or percentage. Differences were calculated for 2004-2008 using t-test, for age and BMI. Differences between ordinal variables were tested using a chi-square test. Abbreviation: BMI, body mass index. 
activities, pain/discomfort, and anxiety/depression, each of which offered three possible responses: "No problems/Some or moderate problems/Extreme problems". The index of EQ-5D was computed according to Burström et al, ${ }^{16}$ ( 1 = full health, $0=$ death).

The factors potentially associated with outcome variables were: age and sex, which are basic factors in all models. In regression analyses, age and body mass index (BMI; body weight divided by the square of height) are standardized.

Economic problems were described by answers to the question: "Have you had difficulties in managing expenditures for food, rent, bills, etc. during the past 12 months?" with the alternatives: "No" or "Yes, 1 month/Yes, 2 months/ Yes, 3-5 months/Yes, 6-12 months"; all Yes-alternatives were classified as "Yes".

Alcohol use was categorized by five categories: "Never/ Once a month or less/2-4 times a month/2-3 times a week/4 times a week or more". Educational level was combined into the categories: "Compulsory school/Grammar school/ University/Other”.

Social support was assessed according to the question: "Do you have any persons in your vicinity who can provide you with personal support in case of personal problems or life crises?" with the alternatives: "Yes, undoubtedly/Yes, probably/Presumably not/No"; where "No" and "Presumably not" were classified as "No".

Smoking status contained four alternatives: "Never smoked/Stopped smoking (ex-smoker)/Intermittent smoker/ Daily smoker". The latter two alternatives were combined to "Current smoker".

Physical activity in leisure time was estimated on a fourcategory scale indicating (A) sedentary (mostly sitting or low activity $<2$ hours a week); (B) moderate exercise (low activity $>2$ hours a week); (C) moderate regular exercise (high activity $>30$ minutes, $1-2$ times a week); (D) regular exercise and training (high activity $>30$ minutes $\geq 3$ times a week).

Health care utilization was indicated by a "Yes" response to the question: "Have you, due to symptoms or disease, visited a doctor in a hospital emergency department during the past three months?" or "Have you, due to symptoms or disease, been admitted to a hospital during the past three months?"

\section{Comorbidity factors}

Comorbidities often associated with COPD were captured by "Yes" answers to the question about presence of longstanding diseases or problems in the last 12 months. These diseases or problems were cardiovascular disease, hypertension, asthma, depression, and chronic fatigue syndrome.

\section{Statistical methods}

For descriptive analysis we used means, standard deviations, and proportions along with $t$-tests and chi-square tests for associations. Regression models were used to analyze the association between health measures (general health status, GHQ12 index, EQ-5D) and a predefined set of explanatory variables. These are added in two blocks for each health measure: block 1 - sex, age, and additional factors (BMI, economic problems, alcohol use, educational level, social support, smoking status, and physical activity), and block 2 - comorbidity factors (cardiovascular disease, hypertension, asthma, depression, and chronic fatigue syndrome). Because there are correlations between comorbidities they are added one at a time in separate analyses. The purpose of block 2 is to see whether comorbidity has any influence on the associations between explanatory variables and outcome.

For GHQ12 we used logistic regression, with odds ratios (OR) and 95\% confidence intervals (95\% CI). For general health we tested the proportional odds assumption in ordinal logistic regression and, when necessary, used partial proportional odds or multinomial regression models instead. All regression analyses for general health were made using the Stata command gologit $2,{ }^{17}$ with automatic testing of the proportional odds assumption both globally and for each variable respectively. For EQ-5D we tested the normal assumption of linear regression. Because the data showed significant deviations, we used median regression instead. ${ }^{18}$

Nonlinear effects of age and BMI were tested using multivariate fractional polynomials (FP). ${ }^{19}$ The estimation routine for fractional polynomials starts with a linear regression model and is expanded when indicated by data, resulting in a parsimonious model still complex enough to describe associations present in data. Associations were measured using odds ratios with $95 \% \mathrm{CI}$.

All analyses were performed using Stata/IC (v 10; Stata Corp LP, College Station, TX).

\section{Ethics}

According to the Swedish laws of medical research ethics, population studies with de-identified personal data do not require ethical approval. The reasoning behind this is that the respondent gave consent when returning the questionnaire.

\section{Results}

The mean age was 69.1 years (females 67.0 and males 69.9 years), and more men than women had self-reported COPD (Table 1). One-third were current smokers, and 28\% of all subjects were daily smokers. A total of $83 \%$ reported 
physical activity on the two lowest levels, and a sedentary lifestyle was stated by $39 \%$. There was no difference in reported physical activity between the years 2004 and 2008. Compulsory school was the highest educational level in $57 \%$ and more than $84 \%$ were retired, on sick leave, or had a sickness pension. Comorbidity was present with cardiovascular disease in 34\%, hypertension, or asthma in more than $40 \%$, depression in $26 \%$, and chronic fatigue syndrome in $22 \%$. More than $23 \%$ had visited an emergency department during the past 3 months, compared with $8 \%-9 \%$ in age-matched subjects without COPD, and 14\% had been admitted to hospital.

General health status was reported as "very good/good" in $24 \%$ (Table 2) and psychological well-being was not impaired in 77\%. Quality of life (EQ-5D) was graded as "no problems" by half the subjects regarding mobility and anxiety/depression, while $14 \%$ had "no problems" with pain/discomfort, and more than $60 \%$ had "no problems" with usual activities. A slightly better status on the health and quality of life measures could be seen in 2008 compared with 2004 (Table 2). Unadjusted relations between self-reported health status and level of physical activity are described in Figure 2.

The regression analyses of self-reported general health diagnostic tests showed deviations from the proportional odds assumption for some variables (age, economic problems, alcohol use, and smoking status) and, as a consequence, partial proportional odds models were used. The heterogeneous associations for these four variables are described in Table 3 as four odds ratios (odds comparing "Very bad" vs "Bad", "Bad" vs "Neither good nor bad", "Neither good nor bad"

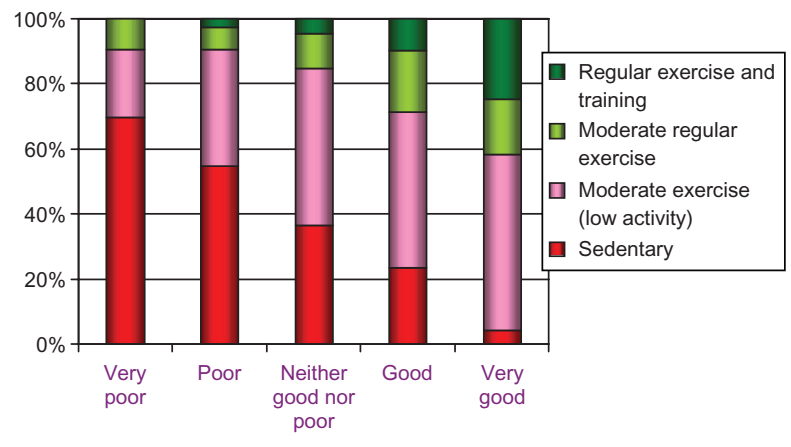

Figure 2 Relationship between self-rated general health (x-axis) and physical activity in leisure time.

vs "Good", and "Good" vs "Very good") for each variable. These odds ratios were interpreted as ordinary odds ratios where, for example, the reference outcome was "Neither good nor bad" the other was "Good". Tests of nonlinear effects for age and BMI only showed significant nonlinear associations for age in the analysis of GHQ12.

Age showed a linear association with self-reported general health, but only when comparing outcome "Good" to "Neither good nor bad" or when comparing "Very good" to "Good". Age showed a U-shaped association with GHQ12 with the lowest odds for having psychological distress at 68 years.

Economic problems were associated with all three health measures, where reporting no economic problems was associated with higher odds for better self-reported general health, lower odds for psychological distress, and increased median of EQ-5D. For self-reported general health the association

Table 2 General health and quality of life $(n=1475)$

\begin{tabular}{|c|c|c|c|c|}
\hline & $\begin{array}{l}\text { Combined } \\
2004+2008 \\
n=I 475\end{array}$ & $\begin{array}{l}2004 \\
n=664\end{array}$ & $\begin{array}{l}2008 \\
n=8 I I\end{array}$ & $P$ value \\
\hline General health status (\%) & & & & 0.038 \\
\hline Very good & 1.7 & 1.5 & 1.9 & \\
\hline Good & 22.0 & 19.5 & 24.1 & \\
\hline Neither good nor poor & 43.9 & 44.8 & 43.3 & \\
\hline Poor & 28.1 & 28.5 & 27.8 & \\
\hline Very poor & 4.2 & 5.7 & 3.0 & \\
\hline GHQ 12; not impaired psychological well-being (\%) & 76.7 & 74.5 & 78.5 & 0.04 \\
\hline EQ-5D index value $[0-1]$ & $0.63(0.27)$ & $0.61(0.28)$ & $0.65(0.26)$ & 0.002 \\
\hline \multicolumn{5}{|l|}{ EQ-5D no problems (\%) } \\
\hline Mobility & 48.6 & 46.9 & 50.1 & 0.11 \\
\hline Self-care & 89.8 & 88.5 & 90.8 & 0.08 \\
\hline Usual activities & 61.3 & 58.6 & 63.5 & 0.03 \\
\hline Pain/discomfort & 13.6 & 12.4 & 14.5 & 0.12 \\
\hline Anxiety/depression & 49.4 & 47.3 & 51.1 & 0.07 \\
\hline
\end{tabular}

Notes: Differences for 2004-2008 were tested using $t$ test for EQ-5D. Differences between proportions were tested using the asymptotic normal test for binomial data. The difference in general health was tested with a chi-square test.

Abbreviations: GHQ 12, General Health Questionnaire I2-item version, impaired well-being defined as present when the total score was 3 or higher; EQ-5D, EuroQol five-dimension questionnaire, index value (standard deviation): [ $\mathrm{I}=$ full health, $0=$ death $]$. 
Table 3 Associations between background factors and measures of general health and quality of life

\begin{tabular}{|c|c|c|c|}
\hline & $\begin{array}{l}\text { General health } \\
\text { OR }(95 \% \mathrm{Cl})\end{array}$ & $\begin{array}{l}\text { GHQI } 2 \\
\text { OR }(95 \% \mathrm{CI})\end{array}$ & $\begin{array}{l}\text { EQ-5D } \\
\text { Effect on median } \\
(95 \% \mathrm{Cl})\end{array}$ \\
\hline Age (standardized) & & $\begin{array}{l}\text { FP U-shaped, minimum } \\
\text { at } 68 \text { years }\end{array}$ & $-0.008(-0.018,0.001)$ \\
\hline Bad vs very bad & I.I $47(0.850,1.547)$ & & \\
\hline Bad/neither good nor bad vs bad & $1.095(0.945,1.269)$ & & \\
\hline Good vs neither good nor bad & $0.828(0.7 \mid I, 0.965)$ & & \\
\hline Very good vs good & $0.454(0.308,0.669)$ & & \\
\hline Sex & I.I $58(0.928,1.445)$ & $\mathrm{I} .054(0.787, \mathrm{I} .4 \mathrm{II})$ & $-0.010(-0.026,0.007)$ \\
\hline BMI (standardized) & I. $103(0.988,1.232)$ & $0.909(0.787,1.050)$ & $0.002(-0.006,0.011)$ \\
\hline \multicolumn{4}{|l|}{ Economic problems } \\
\hline Yes & I (ref) & I (ref) & 0 (ref) \\
\hline No & & $0.372(0.254,0.545)$ & $0.057(0.032,0.081)$ \\
\hline Bad vs very bad & $1.923(0.950,3.894)$ & & \\
\hline Bad/neither good nor bad vs bad & I.082 $(0.740,1.582)$ & & \\
\hline Good vs neither good nor bad & $2.113(1.311,3.406)$ & & \\
\hline Very good vs good & I.I $84(0.375,3.73$ I $)$ & & \\
\hline \multicolumn{4}{|l|}{ Alcohol use the past 12 months } \\
\hline 4 times a week or more & I (ref) & I (ref) & 0 (ref) \\
\hline 2-3 times a week & $1.421(0.911,2.217)$ & $\mathrm{I} .20 \mathrm{I}(0.653,2.2 \mathrm{II})$ & $0.012(-0.021,0.045)$ \\
\hline $2-4$ times a month & $1.452(0.964,2.185)$ & $1.139(0.645,2.012)$ & $0.004(-0.027,0.035)$ \\
\hline Once a month or less & $0.995(0.656,1.508)$ & $1.426(0.809,2.514)$ & $0.001(-0.031,0.032)$ \\
\hline Never & & $1.629(0.9|8,2.89|)$ & $-0.032(-0.063,0.000)$ \\
\hline Bad vs very bad & $0.372(0.186,0.743)$ & & \\
\hline Bad/neither good nor bad vs bad & $\mathrm{I} .02 \mathrm{I}(0.65 \mathrm{I}, \mathrm{I} .602)$ & & \\
\hline Good vs neither good nor bad & $0.958(0.589,1.558)$ & & \\
\hline Very good vs good & $0.476(0.104,2.172)$ & & \\
\hline \multicolumn{4}{|l|}{ Educational level } \\
\hline Compulsory school & I (ref) & I (ref) & 0 (ref) \\
\hline Grammar school & $0.978(0.722,1.326)$ & $1.236(0.826,1.848)$ & $-0.010(-0.033,0.014)$ \\
\hline University & $1.318(0.932,1.863)$ & $1.445(0.933,2.238)$ & $0.014(-0.011,0.040)$ \\
\hline Other & $0.808(0.570,1.146)$ & $1.488(0.964,2.295)$ & $-0.018(-0.044,0.008)$ \\
\hline \multicolumn{4}{|l|}{ Social support } \\
\hline No & I (ref) & I (ref) & 0 (ref) \\
\hline Yes, probably & $1.303(0.853,1.991)$ & $0.632(0.392,1.018)$ & $0.039(0.008,0.070)$ \\
\hline Yes, undoubtedly & $2.060(1.384,3.066)$ & $0.316(0.201,0.495)$ & $0.052(0.023,0.082)$ \\
\hline \multicolumn{4}{|l|}{ Smoking status } \\
\hline Yes, I smoke daily & I (ref) & I (ref) & 0 (ref) \\
\hline Yes, I smoke sometimes & & $1.002(0.530,1.894)$ & $0.014(-0.024,0.052)$ \\
\hline Bad vs very bad & $0.431(0.168,1.102)$ & & \\
\hline Bad/neither good nor bad vs bad & $1.886(0.990,3.595)$ & & \\
\hline Good vs neither good nor bad & I.I $49(0.606,2.180)$ & & \\
\hline Very good vs good & $1.068(0.139,8.198)$ & & \\
\hline No, I have stopped smoking & $\mathrm{I} .08 \mathrm{I}(0.833, \mathrm{I} .404)$ & $0.792(0.568,1.103)$ & $-0.004(-0.023,0.016)$ \\
\hline No, I have never smoked & $1.744(1.184,2.568)$ & $0.528(0.3 \mid 4,0.888)$ & $0.014(-0.015,0.042)$ \\
\hline \multicolumn{4}{|l|}{ Physical activity } \\
\hline Sedentary & I (ref) & I (ref) & 0 (ref) \\
\hline Moderate exercise (low activity) & $2.390(1.869,3.056)$ & $0.549(0.403,0.748)$ & $0.044(0.026,0.062)$ \\
\hline Moderate regular exercise & $3.547(2.434,5.169)$ & $0.538(0.325,0.890)$ & $0.077(0.050,0.104)$ \\
\hline Regular exercise and training & $7.772(4.662,12.968)$ & $0.5 \mathrm{I} I(0.263,0.993)$ & $0.087(0.051,0.123)$ \\
\hline
\end{tabular}


was significant only when comparing "Good" to "Neither good nor bad" health states.

Alcohol use was associated with self-reported general health (only when comparing "Bad" to "Very bad") and weakly associated to EQ-5D. For both measures the reporting of no alcohol use was associated with lower levels of health.

Social support was associated with better status for all three health measures.

Smoking status was significantly associated with higher odds for better self-reported general health and lower odds for psychological distress for those reporting "Never smoked".

Physical activity was associated at all levels with all three health measures. For self-reported general health, the odds of having better health were multiplied by a factor 2.4-7.7 depending on activity level. The odds of being psychologically distressed were reduced by approximately $50 \%$. The median EQ-5D index increased with 0.04-0.09 depending on activity level.

There were no significant associations between the three health measures and sex, BMI, or educational level.

EQ-5D was associated with cardiovascular disease (effect on median $[95 \% \mathrm{CI}]):(-0.05,[-0.07,-0.03])$, depression $(-0.10[-0.13,-0.07])$, and chronic fatigue syndrome $(-0.07$, $[-0.09,-0.05])$, but not with hypertension or asthma.

Psychological distress was associated with depression (OR [95\% CI]): $(6.60[3.92,8.01])$ and chronic fatigue syndrome $(3.77$ [2.61, 5.44]), but not with cardiovascular disease, hypertension, or asthma.

Self-reported general health was associated with cardiovascular disease when comparing "Neither good nor bad" to "Bad" (OR [95\% CI]): (0.39 [0.29, 0.52]) and when comparing "Neither good nor bad" to "Good" $(0.57[0.41,0.80])$ and with asthma $(0.73[0.57,0.95])$ regardless of health state). For depression there were significant associations between self-reported general health and depression (OR range 0.30 0.73 ) and chronic fatigue syndrome (OR range 0.26-0.66), except when comparing "Very good" and "Good". There were no associations between self-reported general health and hypertension.

Adjusting for comorbid conditions (cardiovascular disease, hypertension, asthma, depression, and chronic fatigue syndrome), however, did not alter the associations presented in Table 3 in any significant way.

\section{Discussion}

This study has shown that subjects with COPD when combined with good health and good quality of life were physically active. The higher the physical activity levels the better their health and quality of life. We also showed that even a low level of physical activity was better than a sedentary lifestyle.

Our results were in accordance with Garcia-Aymerich et al who, in an epidemiological study, assessed daily life activities in subjects with COPD and found associations between higher levels of regular physical activity and better functional status. ${ }^{20}$ They also showed that physically active subjects with COPD had a lower risk of COPD admissions and mortality. They proposed that physical activity should be widely recommended for patients with COPD in COPD guidelines. ${ }^{21}$ Our results were also in accordance with those from an asthma population in Canada, ${ }^{22}$ where those with good self-reported health are more physically active. Pitta et al, also showed that encouragement to be more active in daily life is an important part of the management of patients with COPD..$^{23}$

Clinical studies have also shown that patients with COPD spend less time walking and standing compared with age- and sex-matched healthy subjects and activity is on a lower intensity level ${ }^{23}$ that is not sufficient to promote and maintain health. ${ }^{24}$

Multidisciplinary pulmonary rehabilitation is a basis for treatment of COPD, with evidence for improvement in exercise endurance, dyspnea, functional capacity, and quality of life. ${ }^{23}$ Exercise training is a cornerstone of the concept of rehabilitation. ${ }^{2}$ As the majority of patients with COPD are treated in primary care, it is important to make it possible for them to enter programs including physical training in primary care settings. ${ }^{25}$ However, better functional status is associated with daily life activities rather than planned exercise activities, ${ }^{21}$ which is encouraging because regular spontaneous physical activity is easier for most subjects with COPD. In a recent study, Watz et $\mathrm{al}^{26}$ investigated physical activity in patients with COPD and found that physical activity is already reduced from GOLD Stage $\mathrm{II},{ }^{2}$ which suggests that patients spontaneously choose to reduce their activity rather than be restricted by pulmonary limitation, which implies a possible behavioral component that can be influenced.

The present study showed associations between health and quality of life and the factors of social support and absence of economic problems, in line with data reported from general population surveys. ${ }^{14}$ Among older persons with chronic diseases the highest risk for feelings of loneliness is reported for those with lung diseases. ${ }^{27}$

There was a significant association between health, EQ-5D, and teetotalism. This is surprising as there are known relations between smoking and alcohol use, ${ }^{28}$ which could be 
expected to influence health measures in subjects with COPD. The absence of some expected associations could also be interpreted as subjects with COPD, already having the status of limited health and quality of life, were not influenced by additional factors such as alcohol use.

Smoking was common among the subjects with COPD, where $28 \%$ smoked daily. This was a high number compared with smoking in the adult population in Sweden; 11\% of men and $13 \%$ of women are daily smokers. ${ }^{29}$ Thus, there are possibilities to reduce the prevalence of this important risk factor for subjects with COPD. Nonsmoking is a health supporting factor, but there is a worrying trend of higher prevalence of smoking among women, especially in younger age groups. ${ }^{30}$

The design of the present study was cross-sectional and therefore no causal associations could be verified. Compared with studies directly aimed at subjects with respiratory symptoms, this population survey did not contain questions on specific respiratory symptoms, nor were there any instruments enabling grading severity of disease. The response rate in the present study was approximately $65 \%-70 \%$, with a possible underestimation of smoking habits according to a study of nonresponders in a large scale questionnaire survey on respiratory health in Sweden. ${ }^{31}$ There are, however, no signs of bias in disease and symptom prevalence in that study.

The prevalence of self-reported COPD in the present study was low compared with other studies. ${ }^{32}$ The questionnaire did not focus on respiratory problems, however. Moreover, on the diagnosis list, the COPD diagnosis was, perhaps, not the primary diagnosis of choice. This could indicate that subjects with more severe disease, where a COPD diagnosis was clearly expressed, were included in the present study. The high proportion of retired persons or persons on sick leave also supported this assumption. It cannot be stated that our results could be generalized to the total COPD population.

The global perception of health status was, in our study, measured by one question according to the same principle as in other studies. ${ }^{33}$ Idler et al conclude that self-ratings provide the respondents' views of global health status in a way that nothing else can. ${ }^{34}$ Regarding "Patient activity in COPD", Paul W Jones suggests in a review that activity limitation may be a central determinant of impaired quality of life due to poor health, ${ }^{35}$ which also implies an association between activity and health. Quality of life in chronic diseases varies between individuals and within an individual over time and can be described as "the discrepancy between our expectations and our experience". ${ }^{36}$ Montes de Oca et al report that an important proportion of persons with COPD grade their general health as good-to-excellent, and interpret this as "the patients' underestimation of disease severity". ${ }^{33}$ This could, however, be a result of chronically ill patients' adaptation to irreversible changes in their health through lower expectations of quality of life. ${ }^{37}$

\section{Conclusions}

A better self-rated health status and quality of life was associated with higher levels of physical activity, social support, absence of economic problems, and never smoking. The findings indicated that of factors that can be influenced, the promotion of physical activity and the strengthening of social support are important to maintain or improve health and quality of life in subjects with COPD. Severity of the disease as a possible confounding effect should be investigated in future population studies.

\section{Disclosure}

The authors report no conflict of interest in this work.

\section{Acknowledgments}

This study was supported by a research grant from the Swedish Heart-Lung Foundation, the Swedish Heart and Lung Association, and the County Council of Värmland.

\section{References}

1. Halbert RJ, Natoli JL, Gano A, Badamgarav E, Buist AS, Mannino DM. Global burden of COPD: systematic review and meta-analysis. Eur Respir J. 2006;28(3):523-532.

2. Executive Summary: Global strategy for the diagnosis, management, and prevention of chronic obstructive pulmonary disease: GOLD. Available at: http://www.goldcopd.org/. Accessed July 15, 2011.

3. Rennard S, Decramer M, Calverley PM, et al. Impact of COPD in North America and Europe in 2000: subjects' perspective of Confronting COPD International Survey. Eur Respir J. 2002;20(4):799-805.

4. Antonovsky A. Health, Stress, and Coping. 1st ed. San Francisco, CA: Jossey-Bass; 1979.

5. World Health Organization. Ottawa charter for health promotion; First International Conference on Health Promotion. Available at: http:// www.who.int/hpr/NPH/docs/ottawa_charter_hp.pdf. Accessed July 15, 2011

6. Ejlertsson G, Eden L, Leden I. Predictors of positive health in disability pensioners: a population-based questionnaire study using Positive Odds Ratio. BMC Public Health. 2002;2:20.

7. Eriksson M, Lindstrom B. Antonovsky's sense of coherence scale and its relation with quality of life: a systematic review. J Epidemiol Community Health. 2007;61(11):938-944.

8. Arne M, Janson C, Janson S, et al. Physical activity and quality of life in subjects with chronic disease: Chronic obstructive pulmonary disease compared with rheumatoid arthritis and diabetes mellitus. Scand J Prim Health Care. 2009;27(3):141-147.

9. van Manen JG, Bindels PJ, Dekker FW, et al. The influence of COPD on health-related quality of life independent of the influence of comorbidity. J Clin Epidemiol. 2003;56(12):1177-1184. 
10. Al-Shair K, Dockry R, Mallia-Milanes B, Kolsum U, Singh D, Vestbo J. Depression and its relationship with poor exercise capacity, BODE index and muscle wasting in COPD. Respir Med. 2009;103(10):1572-1579.

11. Miravitlles M, Llor C, Naberan K, Cots JM, Molina J. Variables associated with recovery from acute exacerbations of chronic bronchitis and chronic obstructive pulmonary disease. Respir Med. 2005;99(8):955-965.

12. Mackenbach JP, Bos JVD, Joung IMA, Van De Mheen H, Stronks K. The determinants of excellent health: different from the determinants of ill-health? Int J Epidemiol. 1994;23(6):1273-1281.

13. Celli BR, MacNee W. Standards for the diagnosis and treatment of patients with COPD: a summary of the ATS/ERS position paper. Eur Respir J. 2004;23(6):932-946.

14. Molarius A, Berglund K, Eriksson C, et al. Socioeconomic conditions, lifestyle factors, and self-rated health among men and women in Sweden. Eur J Public Health. 2006;17(2):125-133.

15. McDowell I, Newell C. Measuring Health : A Guide to Rating Scales and Questionnaires. 2nd ed. New York: Oxford University Press; 1996.

16. Burstrom K, Johannesson M, Diderichsen F. Swedish population health-related quality of life results using the EQ-5D. Qual Life Res. 2001;10(7):621-635.

17. Williams R. Generalized ordered logit/partial proportional odds models for ordinal dependent variables. Stata Journal. 2006;6(1):58-82.

18. Koenker R. Quantile regression. Cambridge, UK: Cambridge University Press; 2005.

19. Royston P, Sauerbrei W. Multivariable model-building: a pragmatic approach to regression analysis based on fractional polynomials for modelling continuous variables. New York: John Wiley \& Sons, Ltd; 2008.

20. Garcia-Aymerich J, Lange P, Benet M, Schnohr P, Anto JM. Regular physical activity reduces hospital admission and mortality in chronic obstructive pulmonary disease: a population based cohort study. Thorax 2006;61(9):772-778.

21. Garcia-Aymerich J, Serra I, Gómez FP, et al. Physical Activity and Clinical and Functional Status in COPD. Chest. 2009;136:62-70.

22. Dogra S, Baker J. Physical activity and health in Canadian asthmatics. J Asthma. 2006;43(10):795-799.

23. Pitta F, Troosters T, Spruit MA, Probst VS, Decramer M, Gosselink R. Characteristics of physical activities in daily life in chronic obstructive pulmonary disease. Am J Respir Crit Care Med. 2005;171(9):972-977.

24. Nelson ME, Rejeski WJ, Blair SN, et al. Physical activity and public health in older adults: recommendation from the American College of Sports Medicine and the American Heart Association. Med Sci Sports Exerc. 2007;39(8):1435-1445.
25. Chavannes $\mathrm{NH}$, Grijsen $\mathrm{M}$, van den Akker $\mathrm{M}$, et al. Integrated disease management improves one-year quality of life in primary care COPD patients: a controlled clinical trial. Prim Care Respir J. 2009;18(3):171-176.

26. Watz H, Waschki B, Meyer T, Magnussen H. Physical activity in patients with COPD. Eur Respir J. 2009;33(2):262-272.

27. Penninx BWJH, van Tilburg T, Kriegsman DMW, Boeke AJP, Deeg DJH, van Eijk JTM. Social network, social support, and loneliness in older persons with different chronic diseases. J Aging Health. 1999;11(2):151-168.

28. Falk DE, Yi HY, Hiller-Sturmhofel S. An epidemiologic analysis of co-occurring alcohol and tobacco use and disorders: findings from the National Epidemiologic Survey on Alcohol and Related Conditions. Alcohol Res Health. 2006;29(3):162-171.

29. [Tobaksvanor]. Available at: http://www.fhi.se/en/. Accessed July 15, 2011. Swedish.

30. Ali SM, Chaix B, Merlo J, Rosvall M, Wamala S, Lindstrom M. Gender differences in daily smoking prevalence in different age strata: A population-based study in southern Sweden. Scand J Public Health 2009;37(2):146-152.

31. Rönmark EP, Ekerljung L, Lötvall J, Torén K, Rönmark E, Lundbäck B. Large scale questionnaire survey on respiratory health in Sweden: Effects of late- and non-response. Respir Med. 2009;103(12):1807-1815.

32. Lindberg A, Bjerg A, Rönmark E, Larsson L, Lundbäck B. Prevalence and underdiagnosis of COPD by disease severity and the attributable fraction of smoking Report from the Obstructive Lung Disease in Northern Sweden Studies. Respir Med. 2006;100(2):264-272.

33. Montes de Oca M, Tálamo C, Halbert RJ, et al. Health status perception and airflow obstruction in five Latin American cities: The PLATINO study. Respir Med. 2009;103:1376-1382.

34. Idler EL, Benyamini Y. Self-rated health and mortality: a review of twenty-seven community studies. J Health Soc Behav. 1997;38(1):21-37.

35. Jones PW. Activity limitation and quality of life in COPD. COPD. 2007;4(3):273-278

36. Carr AJ, Gibson B, Robinson PG. Measuring quality of life: is quality of life determined by expectations or experience? $B M J$. 2001;322(7296):1240-1243.

37. Voll-Aanerud M, Eagan TML, Wentzel-Larsen T, Gulsvik A, Bakke PS. Respiratory symptoms, COPD severity, and health related quality of life in a general population sample. Respir Med. 2008;102(3):399-406.
International Journal of COPD

\section{Publish your work in this journal}

The International Journal of COPD is an international, peer-reviewed journal of therapeutics and pharmacology focusing on concise rapid reporting of clinical studies and reviews in COPD. Special focus is given to the pathophysiological processes underlying the disease, intervention programs, patient focused education, and self management protocols.

\section{Dovepress}

This journal is indexed on PubMed Central, MedLine and CAS. The manuscript management system is completely online and includes a very quick and fair peer-review system, which is all easy to use. Visi http://www.dovepress.com/testimonials.php to read real quotes from published authors. 